\title{
O uso de partículas modais por alunos recém-alfabetizados que estão escrevendo seus primeiros textos ${ }^{1}$
}

\author{
Cristina Felipeto ${ }^{2}$ \\ Islan Lisboa da Silva ${ }^{3}$ \\ Faculdade de Letras/Programa de pós-graduação em Letras e Linguística, \\ Universidade Federal de Alagoas, Maceió, AL, Brasil
}

Resumo: Este trabalho tem como objetivo principal verificar o uso de partículas modais (PM) em processos de escrita colaborativa dos quais participaram duas alunas recém-alfabetizadas, com idade entre 6 e 7 anos, ao escreverem histórias inventadas. Assume-se como referência central a Linguística da Enunciação representada por Émile Benveniste, para o qual o processo de enunciação dispõe de mecanismos que demandam continuamente do indivíduo uma tomada de posição como sujeito. Os dados utilizados foram produzidos na Escola da Vila, em SP. Foram analisados, ao todo, 16 processos. As alunas formaram uma díade indicada pelo próprio professor e foram filmadas pelo período de 2 anos consecutivos, desde a alfabetização até o 1을 ano. Os resultados mostraram que ao usarem as PM, as alunas buscaram não apenas validar seu papel como enunciadoras, com o objetivo de interferir ou influenciar, mas também que as PM são enunciadas visando sempre o parceiro da enunciação e só ganham sentido a partir da referência interna criada pelos sujeitos no aqui e agora enunciativo.

Palavras-chave: Partículas modais; Escrita colaborativa; Enunciação.

Title: The use of modal particles by newly literate students who are writing their first texts

Abstract: This work aims to verify the use of modal particles (MP) in collaborative writing processes in which two newly literate students, aged between 6 and 7 years, participated in writing invented stories. It is assumed as central reference the Linguistics of Enunciation represented by Émile Benveniste, for which the process of enunciation has mechanisms that continually demand from the individual a positioning as a subject. The data used were produced at Escola da Vila, SP. A total of 16 processes were analyzed. The students formed a dyad indicated by the teacher and were filmed for the period of two consecutive years, from literacy to the first year. The results showed that in using the MP, the students sought not only to validate their role as enunciators, with the purpose of interfering or influencing, but also that the MP are always enunciated aiming at the enunciation partner and only gain meaning from the internal reference created by the subjects in the here and now enunciative.

Keywords: Modal particles; Collaborative writing; Enunciation.

${ }^{1}$ Os dados utilizados neste artigo fazem parte de uma pesquisa mais ampla, cuja entrada no Comitê de Ética da Universidade Federal de Alagoas se deu sob n. 12181113.5.0000.5013 e foi aprovado em 05/02/2013.

${ }^{2}$ Doutora em Linguística, Universidade Federal de Alagoas (UFAL). Orcid: https://orcid.org/00000003-3729-0796

E-mail: crisfelipeto@gmail.com

${ }^{3}$ Mestre em Linguística, Universidade Federal de Alagoas (UFAL). Orcid: https://orcid.org/0000-00017279-9972

E-mail: islanlisboa@yahoo.com.br 


\section{Introdução}

Este trabalho tem como objetivo principal verificar o uso de partículas modais (também chamadas de "expletivas", "enfáticas" ou de "realce") em processos de escrita colaborativa dos quais participaram duas alunas recém-alfabetizadas (I e N, entre 6 e 8 anos de idade) ao escreverem histórias inventadas.

As partículas modais (PM), que figuram como um fenômeno da enunciação, são termos utilizados nas orações em que, a priori, poderiam ser retirados sem que houvesse prejuízo para o seu entendimento.

Ainda são escassos os estudos sobre as PM, sendo pouco comum encontrarmos referências ao uso delas em gramáticas de língua portuguesa. Tal fato constitui, ao mesmo tempo, uma dificuldade e uma oportunidade para trazermos contribuições, sobretudo ao estudarmos as PM produzidas por alunos das séries iniciais que estão escrevendo seus primeiros textos e em situação colaborativa, pois os poucos estudos existentes envolvem sempre enunciados proferidos por adultos.

Para identificarmos e analisarmos essas PM, apoiamo-nos em um material coletado durante 2 anos (entre 1991 e 1992), cujos processos fazem parte do banco de dados "Práticas de textualização na escola - PTE", pertencente ao Laboratório do manuscrito escolar (L'AME). Essas duas alunas frequentavam uma escola particular de São Paulo e participaram de 16 filmagens de escrita colaborativa. Todos os processos foram filmados e transcritos, e, por se tratar de escrita colaborativa, na qual dois ou mais participantes assumem a tarefa de escrever um único texto conjuntamente, tivemos a possibilidade de analisar o diálogo ocorrido durante a escrita dos textos, o que Gaulmyn, Bouchard e Rabatel (2001) chamam de situação "dialográfica", uma "circunstância privilegiada", pois se pode observar:

situações em que o escrito nasce do oral e em que o oral serve para criar o escrito, [o que] oferece um ponto de vista privilegiado sobre o processo de produção escrita e sobre o estabelecimento da competência plural, escrita e oral do locutor letrado (p. 09).

Em particular, este trabalho assume como referência central a Linguística da Enunciação representada por Émile Benveniste, para o qual o processo de enunciação dispõe de mecanismos que demandam continuamente do indivíduo uma tomada de posição como sujeito. Buscaremos mostrar de que modo as partículas modais mostram essa tomada de posição. 


\section{As partículas modais}

As partículas modais estão presentes não somente na língua falada cotidianamente, mas também em textos escritos. Elas têm uma marcante função comunicativa, realçando o enunciado através de seu caráter modalizador e podem ser retiradas do enunciado sem que se constituam frases sintática e semanticamente inaceitáveis. São exemplos de partículas modais "enfim", "acaso", "e", "afinal", "então", "já", "lá" etc. ${ }^{4}$

Fernandes (1998) destaca que desde Dionísio de Trácio (séc. I a. C.), os gramáticos se deram conta de que havia na língua palavras que não se integravam facilmente a nenhum grupo (advérbio, conjunção, preposição, pronome, interjeição...), pois desempenhavam outras funções, por isso, as colocaram como um subconjunto das conjunções, dando-lhes o nome de expletivas.

Palavra derivada de uma raíz indo-europeia, ple, "estar cheio", expletivo, particípio passado de explere, "encher" é usada para designar um elemento da fala que serve apenas para dar realce. Seria a palavra que enfatiza a frase, sem ser-lhe, no entanto, fundamental.

Fernandes (1998) afirma que já no século I d. C., Apolónio Díscolo analisa a função desempenhada pela "conjunção" expletiva e conclui que "elas são tão ou mais importantes que quaisquer outras conjunções" (p. 83) porque encerram mais de um significado (restrição, oposição, transição etc). O autor ressalta ainda que Pompeio (século IV d. C), ao comparar frases com/sem a presença das expletivas, observou que sua presença/ausência "acarreta alterações semântico-pragmáticas evidentes" (p. 83), a depender do contexto em que são utilizadas.

Franco (1990), além de cunhar o termo "partículas modais" e abordá-las sob uma perspectiva pragmática, mostra como algumas destas palavras são classificadas tradicionalmente (e erroneamente) pelas gramáticas portuguesas como advérbios, interjeições ou, ainda, categorizadas como expressões ou partículas de realce.

De acordo com o autor, a língua portuguesa não se enquadra na categoria daquelas línguas em que as partículas são abundantes (como o alemão, o holandês, o russo) e nem das que não as possuem e, embora as PM portuguesas ainda sejam colocadas em segundo plano pelos lexicógrafos, essa categoria é diversificada: "a língua portuguesa faz uso de tais partículas, a cada uma das quais é, aliás, possível, por sua vez, fazer corresponder um espectro por vezes largo de equivalências funcionais em alemão" (1988, p. 138).

A fim de explicar essa problemática das PM, Franco (1990) traça um estudo diacrônico, desde a Grécia Antiga, onde já se começava a diferenciar e a definir as partes do discurso, passando pelos gramáticos latinos, que se limitaram a seguir os gregos e "não

\footnotetext{
${ }^{4}$ Exemplos retirados de Ramos (2000): "Tenho lá contas e forças para tal orçamento, velho?", "Então, para que serve uma mulher?", "E é preciso ser histérica?", "Onde estava afinal a sua fé?", "Acaso acham isso bonito?".
} 
dedicaram atenção especial a certas palavras empregadas frequentemente na linguagem falada" (p. 176).

As partículas modais permaneciam, portanto, dispersas por categorias distintas e até mesmo ausentes das gramáticas normativas, o que chamou a atenção de alguns pesquisadores contemporâneos, dentre eles, Ramos (2000), que aborda a escassez de referências gramaticais acerca dos estudos sobre as PM:

Lembremos que, talvez por pertencerem sobretudo ao domínio da linguagem falada, ainda pouco estudada entre nós e muitas vezes relegada para planos inferiores numa eventual escala de prestígio social, ainda é muito raro encontrarmos referência nas gramáticas portuguesas às PM (p.4).

Para Ramos, essas partículas podem parecer como "dispensáveis" ao ato enunciativo, mas apenas se forem analisadas sob uma ótica sintática ou através de critérios semânticos formais. Observemos o exemplo ${ }^{5}$ abaixo:

Fragmento 1 - História inventada "As ermã":

(1) N: (escrevendo 'Laura') Lau...ra... como que se escreve mesmo? É "erre" e "a"?..

(2) I: Você é que sabe

(3) N: Por quê?

(4) I: Porque é você que está escrevendo (riem).

Neste exemplo, retirado dos nossos dados, I faz uso de partículas modais em mais de um momento. Em (2) e (4), ela emprega a locução modal "é que" para enfatizar que precisa ser do jeito de $\mathrm{N}$, que é quem está escrevendo. Se observarmos o mesmo exemplo, desta vez sem as PM, perceberemos que a exclusão destas não torna o enunciado inaceitável de um ponto de vista semântico formal, mas o sentido se altera:

(1) N: (escrevendo "Laura") Lau...ra... como que se escreve mesmo? É "erre" e "a"?

(2) I: Você sabe

(3) N: Por quê?

(4) I: Porque você está escrevendo (riem).

Agora, observemos o turno 2 desse exemplo, com e sem a locução modal "é que".

(2) I: Você é que sabe

(2) I: Você sabe

\footnotetext{
${ }^{5}$ Entre parênteses encontra-se a contextualização e, entre colchetes, quando houver, encontra-se o
} que a aluna está escrevendo naquele momento. 
O "é que" focaliza a atenção sobre o segmento que lhe é imediatamente anterior, "você". Assim, ao dizer apenas "você sabe", o sentido se vê alterado, pois se trata de uma afirmação, ao passo que, "você é que sabe" trata-se de dizer que $\mathrm{N}$ é que decide, que ela pode fazer do jeito que quiser, pois está escrevendo, independentemente de ela saber, de fato, ou não. Como diz Ramos (2000), "onde o seu valor se verifica é ao nível semânticopragmático, como marcadores de um certo tipo de modalidade, e aí assumem um papel de verdadeira importância comunicativa" (p. 05).

Quer dizer, as PM são meios de expressão das intenções do falante e através delas se procura (e se obtêm) certos efeitos comunicativos. Por serem em alto grau sensíveis à situação e ao contexto, sua abordagem por um viés enunciativo, como o adotado neste estudo, revela-se bastante adequada. Para Figueredo (2015), as PM podem atuar como "coringas" no ato enunciativo, ora assumindo uma ou outra função. Sob a ótica da teoria sistêmico-funcional, o autor assim as classifica, segundo suas funções:

Quadro 1 - Descrição das PM - classificação e função - a partir de Figueredo (2015)

\begin{tabular}{|c|c|c|}
\hline Classe & Função & Exemplo \\
\hline Atenção & $\begin{array}{l}\text { Requerer especial foco do ouvinte } \\
\text { para ser validada }\end{array}$ & $\begin{array}{l}\text { Ó, depois que eu falar com ele eu te conto o } \\
\text { sonho }\end{array}$ \\
\hline Anuência & $\begin{array}{l}\text { Pedir ao ouvinte que a proposição do } \\
\text { falante possa se tornar parte do } \\
\text { "conhecimento compartilhado", } \\
\text { ainda que não o seja, de fato }\end{array}$ & $\begin{array}{l}\text { A: Então... Chega, né? } \\
\text { B: Né? } \\
\text { A: É. Porque não vai dar em nada, né? } \\
\text { B: É. Já deu o que tinha que dar. }\end{array}$ \\
\hline Concordância & $\begin{array}{l}\text { Pedir ao ouvinte que compartilhe } \\
\text { não apenas o conhecimento, mas } \\
\text { também o valor apresentado pela } \\
\text { proposição }\end{array}$ & Não vai ficar bonito igual o outro não, tá? \\
\hline Insistência & $\begin{array}{l}\text { Conduzir o ouvinte a validar a } \\
\text { proposição de forma que seja } \\
\text { respondida da forma esperada pelo } \\
\text { ouvinte }\end{array}$ & $\begin{array}{l}\text { (A) Não deve de ser para ligar para elas. } \\
\text { (B) Eu acho que é sim, sô. } \\
\text { (A) É? }\end{array}$ \\
\hline Conclusão & $\begin{array}{l}\text { Levar o ouvinte a endossar a } \\
\text { proposição, pressupondo que } \\
\text { valores e conhecimentos não } \\
\text { precisariam ser negociados, pois que } \\
\text { evidentes }\end{array}$ & $\begin{array}{l}\text { (A) Ela não sabe lavar um copo! } \\
\text { (B) Ela não faz nada. } \\
\text { (A) Ela não sabe lavar um copo, ué. }\end{array}$ \\
\hline Entendimento & $\begin{array}{l}\text { Fazer o falante reconhecer uma } \\
\text { decisão e dar-lhe anuência, sob ares } \\
\text { de uma "negociação" }\end{array}$ & $\begin{array}{l}\text { (A) Que vergonha! Vocês nunca mais voltam } \\
\text { pro lado de lá, viu? } \\
\text { (B) Viu. }\end{array}$ \\
\hline Confirmação & $\begin{array}{l}\text { Construir uma proposição para que o } \\
\text { movimento respondente seja } \\
\text { esperado. Por isso, precisa que o } \\
\text { ouvinte confirme }\end{array}$ & $\begin{array}{l}\text { (A) Nós vamos estudar a teoria do delito e } \\
\text { nós vamos estudar... você grava as minhas } \\
\text { aulas, é? } \\
\text { (B) Gravo. }\end{array}$ \\
\hline
\end{tabular}

${ }^{6} \mathrm{O}$ autor descreve o entendimento da seguinte forma: "necessita que o ouvinte não dê apenas anuência, mas negocie a motivação do falante para colocar essa proposição, e não outra, em negociação" (2015, p. 297). Nós, porém, preferimos esta explicação, por acharmos que condiz mais com o exemplo em questão. 
Quadro 1 (continuação) - Descrição das PM - classificação e função - a partir de Figueredo (2015)

\begin{tabular}{|c|c|c|}
\hline Empatia & $\begin{array}{l}\text { Receber na negociação um } \\
\text { argumento respondente esperado, } \\
\text { ou a empatia do ouvinte }\end{array}$ & $\begin{array}{l}\text { "O senhor tem mio aí pra vender?" Aí ele } \\
\text { respondeu: "'mio' eu não tenho não. Eu } \\
\text { tenho 'milho'. Hmm, menino, mas aquilo me } \\
\text { deixou enfezado um tanto, sô. }\end{array}$ \\
\hline Exclamação & $\begin{array}{l}\text { Realizar alguma alteração no estado } \\
\text { emocional do falante que sinaliza } \\
\text { para o ouvinte essa alteração }\end{array}$ & Oxente, quem tá ligando pra isso? \\
\hline Exortação & $\begin{array}{l}\text { Levar o ouvinte a (i) obedecer a um } \\
\text { comando, ou (ii) a fornecer uma } \\
\text { informação. Assim, incentiva o } \\
\text { ouvinte a obedecer ou responder, } \\
\text { aumentando a probabilidade de } \\
\text { sucesso da negociação }\end{array}$ & $\begin{array}{l}\text { Ex } 1 \text { Exortação para responder: } \\
\text { (A) Ah. Não, não é isso. } \\
\text { (B) Então o que é, tchê? } \\
\text { Ex } 2 \text { Exortação para obedecer: } \\
\text { Sobe logo nesse carro, tchê. }\end{array}$ \\
\hline Atenuação & $\begin{array}{l}\text { Atenuar a força dos comandos, } \\
\text { aumentando, dessa maneira, a } \\
\text { chance de a proposta ser obedecida } \\
\text { ou aceita }\end{array}$ & Não, espera aí, me dá uma faca aí. \\
\hline
\end{tabular}

Fonte: elaboração própria

A partir dessa classificação, Figueredo (2015) demonstra como as PM regulam os papéis do falante e do ouvinte, promovendo uma solidariedade entre eles: "Cabe ao falante convidar o interlocutor a 'endossar e compartilhar', bem como estabelecer seu grau de envolvimento na fala" (p. 300), de modo que, através da validação, o falante não apenas valida o que está dizendo, mas também abre espaço para que o ouvinte o faça.

\section{Partículas modais e enunciação}

As partículas modais constituem um importante instrumento enunciativo, sendo abundantes na espontaneidade dos diálogos cotidianos, nos quais locutor e alocutário (sendo este real ou imaginado) demarcam sua posição e sua intenção comunicativa dentro do enunciado.

No quadro enunciativo benvenistiano, a subjetividade é "a capacidade do locutor para se propor como sujeito" (BENVENISTE, 1991, p. 286), de modo que o locutor se e(a)nuncia ao enunciar "eu", por um lado, e através de "índices específicos" (2006, p. 84), formas que toda língua possui, por outro, tais como os pronomes pessoais, a dêixis e alguns verbos. A enunciação ocorre em um espaço (hic) e um tempo (nunc), constituído por um eu (ego). Tomando como base esse quadro, tais condições de produção jamais se repetirão novamente, pois cada ato é único, irrepetível. O eu somente deixa de ser eu quando o tu toma a temporalidade e o espaço da fala.

Observamos, desse modo, a intersubjetividade constitutiva da língua e a reversibilidade entre eu e tu, matriz do diálogo: 
Essa condição de diálogo é que é constitutiva da pessoa, pois implica em reciprocidade - que eu me torne tu na alocução daquele que por sua vez se designa por eu. [...] A linguagem só é possível porque cada locutor se apresenta como sujeito, remetendo a ele mesmo como eu no seu discurso. Por isso, o eu propõe outra pessoa, aquela que, sendo embora exterior a mim, torna-se o meu eco - ao qual digo tu e o que me diz tu (BENVENISTE, 1991, p. 286, grifos do autor).

Nesse quadro enunciativo, a oralidade instancia a linguagem, vinculando o locutor e o alocutário em um jogo marcado por relações intersubjetivas, que atuam produzindo sentidos no discurso, onde eu e tu propiciam e estruturam o diálogo. Conforme Benveniste, essas "duas figuras na posição de parceiros são altamente protagonistas da enunciação. Esse quadro é dado necessariamente como a definição da enunciação" (2006, p. 87).

Com essa definição do que é a enunciação, Benveniste aponta para a necessidade de se estudar a língua em uso, em ação, e cada instância de uso é única e individual. Os trabalhos de Benveniste nos fornecem subsídios interessantes para compreendermos a situação didática dialográfica em que se encontram os alunos (discutindo e escrevendo colaborativamente um mesmo texto), as trocas de posições e as tentativas de influenciar um ao outro através de estratégias as mais diversas.

Para influenciar o parceiro há, segundo Benveniste, um aparelho de funções, como "formas lexicais e sintáticas da interrogação, partículas, pronomes, sequência, entonação, etc." (2006, p. 86, ênfase nossa). É por isso que defendemos as partículas modais como aquilo que implica uma relação no aqui e agora com o outro. Se observarmos o quadro 1 (descrição das PM, acima) veremos que as partículas modais ali descritas (tchê, sô, ó, tá, etc.), se isoladas, são desprovidas de sentido, são enunciadas visando sempre o parceiro da enunciação (ainda que este seja o próprio eu) e só ganham sentido a partir da referência interna construída pelos sujeitos em ação.

\section{Características do Corpus}

Para o desenvolvimento de projetos e coleta de dados em sala de aula, temos privilegiado a escrita colaborativa, pois ela permite que tenhamos acesso a todo o processo de produção textual, colocando o diálogo como matriz de nossas análises. Além disso, a escritura compartilhada e face-a-face propicia a interação, potencializa o diálogo, sua captura foi realizada através de áudio e vídeo e foi posteriormente transcrita. Assim, é possível monitorar em tempo e espaço real o processo de produção do manuscrito escolar, observando o caminho que os escreventes percorrem até chegarem ao produto final, o texto acabado. 
Os dados que utilizamos em nossa pesquisa ${ }^{7}$ foram produzidos na Escola da Vila, em $\mathrm{SP}$, entre 1991 e 1992. Foram analisados, ao todo, 16 processos. As alunas ( $\mathrm{N}$ e I) formaram uma díade indicada pelo próprio professor e foram filmadas pelo período de 2 anos consecutivos, desde a alfabetização até o 10 ano. Quando as filmagens iniciaram, I tinha 6 anos e 5 meses e N, 5 anos e 9 meses.

A escola assumia uma concepção teórico e didática sócio-construtivista, valorizando significativamente o trabalho em grupo de alunos. As propostas de produção de texto eram feitas regularmente organizando os alunos em grupos ou em pares, que já estavam familiarizados com trabalhos em pequenos grupos desde os anos anteriores.

Um dos critérios para a seleção desta díade foi o fato de serem amigas (critério de afinidade) e expansivas. Além disso, os pais estavam de acordo com o registro fílmico de suas filhas. Inicialmente, a consigna era apresentada às alunas e se estabelecia quem seria o responsável por escrever e quem seria o responsável por "lembrar" o que havia sido combinado.

Também ficou estipulado que as alunas escreveriam de modo alternado, ou seja, uma escrevendo e a outra ditando, revertendo o papel a cada vez. No segundo momento, as alunas pensavam a história e recebiam o papel e a caneta quando informavam ao professor que a história já havia sido combinada. O terceiro momento é o momento em que as alunas registravam no papel aquilo que havia sido combinado, elaborado mentalmente. No quarto momento, as alunas reliam tudo o que fora inscrito e produziam novas alterações, caso considerassem necessário.

\section{Incidências e funções das PM nos processos observados}

Apresentaremos abaixo algumas PM encontradas nos processos analisados, buscando classificá-las a partir da proposta de Figueredo (2015) e compreendê-las em um quadro teórico enunciativo, para o qual a intersubjetividade é a característica constitutiva do diálogo e este, a matriz da enunciação. Todas as classes de PM foram encontradas nos processos, conforme mostra o gráfico abaixo:

\footnotetext{
${ }^{7}$ Estes dados fazem parte do banco de dados PTE - práticas de textualização na escola que tem sido formado e organizado desde 1996 por Calil (pesquisador CNPq), contando atualmente com mais de 2.500 manuscritos.
} 
Figura 1 - Tipos de Partículas Modais nos processos analisados

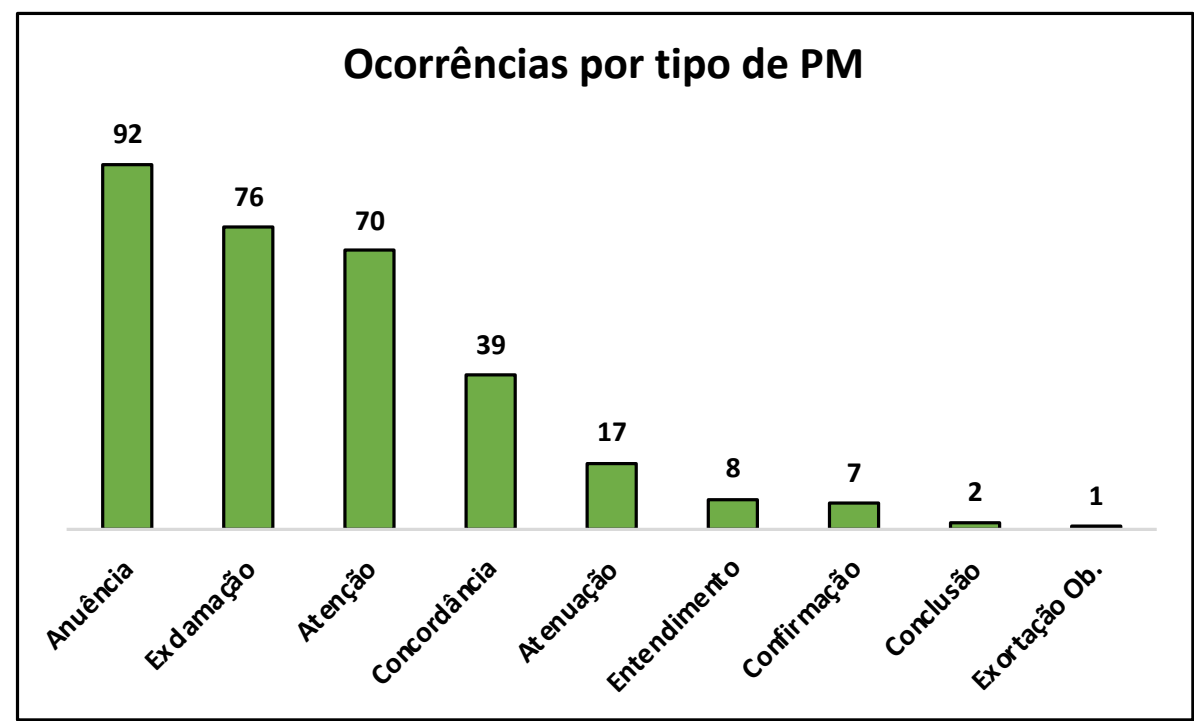

Fonte: Laboratório do Manuscrito Escolar

Como se pode observar, a figura 1 apresenta a quantidade de ocorrências em todos os processos analisados. Foram 312 partículas modais, sendo a PM que indica anuência, a que teve maior ocorrência nos manuscritos produzidos pela díade, totalizando 92 acontecimentos, seguido por 76 casos indicando exclamação, 70 de atenção, 39 de concordância, dezessete usos indicando atenuação, oito de confirmação, sete usos de PM que sinalizam entendimento, dois casos de conclusão e apenas uma ocorrência de exortação para obedecer.

Figura 2 - Ocorrências de Partículas Modais nos textos analisados

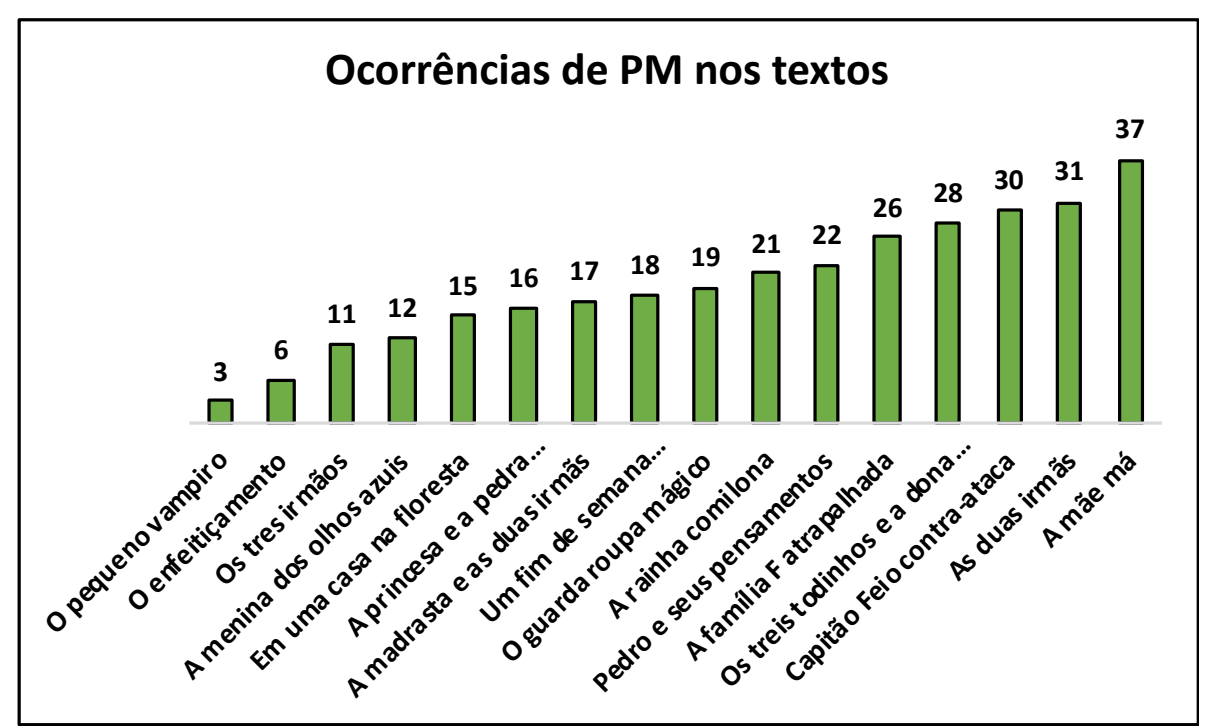

Fonte: Laboratório do Manuscrito Escolar 
Na figura 2, mostramos as ocorrências de PM por texto. O mais rico em uso de partículas modais foi a produção intitulada "A mãe má", somando um total de 37 PM utilizadas ao longo do texto. "As duas irmãs" contou com o uso de 31 partículas, "Capitão Feio contra-ataca", com 30. E a partir daí, tivemos um decréscimo na ocorrência de PM nos textos observados.

"Os três todinhos e a dona sabor" apresentou 28 ocorrências; "A família F atrapalhada" contou com 26; "Pedro e seus pensamentos", 22; "A rainha comilona", 21; "O Guarda roupa mágico" totalizou dezenove PM; "Um fim de semana atrapalhado", dezoito; "A madrasta e as duas irmãs", dezessete; "A princesa e a pedra encantada" obteve dezesseis casos; "Em uma casa na floresta", quinze; "A menina dos olhos azuis", doze casos; "Os três irmãos", onze casos; "O enfeitiçamento" somou seis ocorrências; e "O Pequeno vampiro" foi o texto mais pobre em ocorrência de PM, contendo apenas três casos.

Por questões de limites de espaço, mostraremos exemplos das três primeiras classes, a de anuência, de exclamação e de atenção, que ocorreram em maior número e que correspondem, respectivamente, a $30 \%, 24 \%$ e $23 \%$ do total de ocorrências.

Fragmento 2 - História inventada "A madrasta e as duas irmãs":

$\mathrm{N}$ e l estão sentadas em suas carteiras quando começam a combinar a história.

(1) N: Eu que dito, tá?

(2) I: Ah, ela que vai falar (falando para a professora e apontando para N).

Neste formato de escrita colaborativa, a alternância entre quem escreve e quem dita é colocada como regra desde o início, muito embora observemos que a caneta troque de mãos muitas vezes durante o processo de escrita. Aqui, logo no início da combinação da história, $\mathrm{N}$ trata logo de informar que, como ela escreveu da última vez, desta vez ela irá ditar. I logo repassa essa informação à professora, o que funciona como um ato de concordância. A PM "tá?" presente no turno 1, não apenas dá a conhecer essa informação à I, mas ainda conclama ao seu compartilhamento e aceitação.

Assim, o enunciador vai negociar a validação do que foi falado, junto ao seu enunciatário, compartilhando assim, o valor da proposição. Conforme ilustramos no início, aqui percebemos a importância modalizadora das partículas. Sem ela no enunciado, teríamos uma construção mais rígida, tornando-se um comunicado "Eu que dito" e não uma proposição de concordância.

Fragmento 3 - História inventada "A rainha comilona":

(1) N: É... a madrinha falou "tá bom" e ela falou "tá bom, madrinha"... (rindo)

(2) I: Ah, vai N... vai pensando aí, vai pensando

(3) N: ...e ela já vai falava... 
(4) I: Ah, vai N...

Neste fragmento, observamos I cansar-se das brincadeiras de $\mathrm{N}$ e manifestar esse seu sentimento censurando-a. Neste caso, a PM é de exclamação e demonstrou a alteração no estado emocional do enunciador (I) que, ao produzir uma proposição, sinalizou para o enunciatário $(\mathrm{N})$ essa alteração, representado aqui pela PM "ah". Ela equivale, aqui, a "pare com isso".

Fragmento 4 - História inventada "A madrasta e as duas irmãs":

(1) I: A mágica vai dar para mãe de Adriana para ficar com uma dó... (S.I.) prá ficar com dó dela... prá ficar com ela, tá? Cabum ma... [CABUM MA] machalabum... macha... [CHALABUM]

(2) N: Ó o tanto que a gente escrevemo I... (apontando para o texto)

(3) I: tô... a gente?

(4) N: é... é... você...

No fragmento acima, vemos I concentrada no que está escrevendo e $\mathrm{N}$ buscando chamar-lhe a atenção através da PM "ó" para mostrar que já haviam escrito muito (turno 2). De acordo com o esquema de classificação traçado por Figueredo (2015), a função de atenção é usada tanto com proposições, quanto com propostas ${ }^{8}$. Sua função, dentro deste enunciado, é solicitar especial foco do seu enunciatário, para que seja validada. I atende ao chamado e reage (turno 3) com um questionamento ("a gente?") lembrando que, como é ela quem está, de fato, escrevendo, então $\mathrm{N}$ deveria repensar a proposição "a gente". $\mathrm{N}$, por sua vez, reformula (turno 4) ao dizer "é... é... você...".

As PM que foram mostradas nos dados acima (tá?, ah, ó) foram enunciadas visando o outro da enunciação, neste caso especificamente, o outro parceiro da escrita em colaboração, com os objetivos de demandar concordância, demonstrar alteração de um estado emocional e chamar a atenção, respectivamente. É interessante apontar, aqui, o estatuto altamente subjetivo das $\mathrm{PM}$ e sua dependência com relação ao contexto da enunciação.

Benveniste afirma, com relação à dêixis, que ela é contemporânea ao eu que enuncia, isto é, trata-se de uma categoria vazia que se torna "plena" a partir do ato de enunciação, em que o enunciador atua como parâmetro para que os dêiticos façam sentido. Diferentemente dos dêiticos, para as PM, a referência é a própria enunciação, uma vez que não é possível saber a que se refere um "ué", "é que", "tchê", etc., a não ser a partir do diálogo, a partir da referência interna criada pelos sujeitos no momento da enunciação.

\footnotetext{
${ }^{8}$ Segundo Gouveia, "umá proposição é algo que pode ser refutado - algo que pode ser afirmado ou negado, posto em dúvida, contrariado, contraditado, aceitado, rejeitado, etc. - mas uma proposta não pode ser afirmada ou negada. Sistematizando: a função semântica de uma oração na troca de informação é uma proposição; a função semântica de uma oração na troca de bens \& serviços é uma proposta" (2009, p. 35).
} 


\section{Conclusão}

Dentro do escopo e dos objetivos desta pesquisa, espera-se ter sido possível mostrar o valor pragmático das PM, que atuam como um importante elemento retórico, pois seu uso demarca a posição do sujeito junto ao enunciado. Ainda que, equivocadamente, o uso de tais partículas seja rotulado como desnecessário, seu caráter modal nos diz outra coisa, pois, como já havia percebido Apolónio Díscolo no séc. I d. C., estas partículas são "polifuncionais e [...] seu sentido está dependente do contexto em que se inserem" (FERNANDES, 2004, p. 154). Retomemos uma parte do fragmento 1 , apresentado no início desta pesquisa:

Fragmento 1 - História inventada "As ermã":

(1) N: (escrevendo "Laura") Lau...ra...como que se escreve mesmo? É "erre" e "a"?

(2) I: Você é que sabe

Ora, percebemos que não se trata, para I (turno 2) de informar à $\mathrm{N}$ que ela sabe, mas que ela deve "fazer como quiser", "do seu jeito", independentemente de saber ou não. A mesma locução modal "é que", em outro contexto, como, por exemplo, "E eu é que sei?" assume outra função, a de atenuação, pois o locutor, ao se sentir ofendido por alguma asserção anteriormente enunciada, atenua esse grau de ofensa.

Figueredo (2015) afirma que "as PM constroem cadeias coesivas de argumentação ao longo do diálogo e acumulam significado interpessoal ao longo do texto" (p. 305), regulando os papéis do falante e do ouvinte. Este significado interpessoal só pode ser recuperado no aqui e agora da enunciação. Por isso, a retirada de "é que" pode não tornar a frase inaceitável do ponto de vista semântico formal, mas ela perde sua essência enunciativa.

Ao analisarmos o que diz Franco (1990), que as PM "se caracterizam pelo fato de com o seu auxílio o falante exprimir (e obter) certos efeitos comunicativos e dar expressão a determinadas pressuposições" (p. 188), vemos aí toda a força da afirmação de Benveniste para o estudo das PM, ao tratar de definir o que é o Plano do Discurso:

... toda enunciação que suponha um locutor e um ouvinte e, no primeiro, a intenção de influenciar, de algum modo, o outro [desde] a diversidade dos discursos orais de qualquer natureza e de qualquer nível [até] todos os gêneros nos quais alguém se dirige a alguém, se enuncia como locutor e organiza aquilo que diz na categoria de pessoa (1991, p. 267).

Cada vez que usamos "tá?", "né?" ou, ainda, "viu?", estamos em processo de negociação de proposições ou propostas, em busca não apenas da validação de nosso papel como falante nos turnos, buscando interferir ou influenciar, mas também cedendo espaço 
para que o ouvinte, por sua vez, também atue da mesma maneira. Com relação às "alterações semântico-pragmáticas evidentes" das quais Pompeio se apercebeu no século IV d. C. ao falar das partículas modais, o sujeito falante logo cedo se dá conta delas e dos efeitos que elas produzem sobre o outro, que é o que esperamos ter mostrado ao analisar o uso de partículas modais por alunos recém-alfabetizados que estão escrevendo seus primeiros textos.

\section{Referências}

BENVENISTE, É. As relações de tempo no verbo francês. Problemas de Linguística Geral I. Campinas, SP: Pontes, p. 260-276, 1991.

BENVENISTE, É. Da subjetividade na linguagem. Problemas de Linguística Geral I. Campinas, SP: Pontes, p. 284-293, 1991.

BENVENISTE, É. O aparelho formal da enunciação. Problemas de linguística geral II. Campinas, SP: Pontes, p. 81-90, 2006.

FERNANDES, G. Partículas discursivas do português. Revista de Letras II. Vila Real: Universidade de Trás-Os-Montes e Alto Douro, v. 8, n. 1, p. 83-93, 1998.

FERNANDES, G. Das conjunções expletivas do grego e do latim às partículas discursivas do Português. Actes du XXIV Congrès International de Linguistique et de Philologie Romanes. Aberystwyth, p. 151-163, 2004.

FIGUEREDO, G. Uma descrição sistêmico-funcional dos marcadores discursivos avaliativos em português brasileiro: a gramática das partículas modais. ALFA: Revista de Linguística, v. 59, n. 2, p. 281-307, 2015. https://doi.org/10.1590/1981-5794-1504-3

FRANCO, A. C. Partículas modais do português. Revista da Faculdade de Letras: Línguas e Literaturas, série II, p. 175-196, 1990.

FRANCO, A. C. Partículas modais da língua portuguesa: relances contrastivos com as partículas alemãs. Revista da Faculdade de Letras: Línguas e Literaturas, série II, vol. 5, tomo 1 (1988), p. 137-156, 2012.

GAULMYN, M. M. BOUCHARD, R; RABATEL, A. Le Processus rédactionnel. Ecrire à plusieurs voix. Paris, L'Harmattan, 2001.

GOUVEIA, C. A. M. Texto e gramática: uma introdução à linguística sistêmico-funcional. Revista Matraga, v. 16, n. 24, p. 13-47, 2009.

RAMOS, R. L. As Partículas Modais como co-indicadores ilocutórios: o caso das perguntas retóricas. Anais do XV Encontro Nacional da Associação Portuguesa de Linguística, Universidade do Minho, Portugal, p. 1-20, 2000.

Recebido em: 04/10/2018

Aceito em: 19/02/2019 